\title{
NATUREZA JURÍDICA DO DIREITO AMBIENTAL: NORMAS DE SOBREDIREITO E COMPETÊNCIA MUNICIPAL DE NATUREZA LOCAL, UMA AVALIAÇÃO SOB O PRISMA PRINCIPIOLÓGICO
}

\author{
LEGAL NATURE OF ENVIRONMENTAL LAW: SUPERLAW STANDARDS AND \\ COMPETENCE OF MUNICIPAL LOCAL NATURE, AN ASSESSMENT UNDER THE \\ PRISM OF ENVIRONMENTAL PRINCIPLES.
}

Marcos Batista GUIMARÃES*

Paulo Ricardo da Rocha ARAÚJO**

\section{RESUMO:}

O presente artigo tem como escopo realizar uma reflexão quanto à atuação dos munícipes/municípios nas construções sociológicas/societárias referentes à preservação/conservação dos recursos naturais. Esta construção indica uma relação característica entre o espaço/território quanto às mudanças de paradigmas na aplicação das legislações ambientais vigentes, realizando-se para tal o esgarçamento jusfilosófico e ético, no que tange a hermenêutica das emanações do Direito Ambiental e Constitucional. Para tal, enfatiza-se a característica do Direito Ambiental como norma de Sobredireito, sob o prisma dos princípios que regem esta ciência, abrangendo os aspectos gerais da Justiça Ambiental, Governança Ambiental e Direito Humano Fundamental, em confronto com as Competências Materiais e Legislativas conferido aos entes da federação, respeitado-se o Princípio Federativo.

\section{PALAVRAS-CHAVE:}

Direito Ambiental; Princípio Federativo; Competência; Sobredireito; Município.

\section{ABSTRACT:}

This article is scoped to perform a reflection on the performance of citizens and municipalities in sociological and societal constructs regarding the preservation or conservation of natural resources. This construction indicates a characteristic relationship between the space territory regarding changes of paradigms in the implementation of existing environmental legislation, where the rupture with legal philosophy and ethical, with regard to hermeneutics of emanations of Constitutional and environmental law. To this end, emphasizes the feature of

\footnotetext{
* Mestre em Planejamento e Gestão Ambiental na Universidade Católica de Brasília, Brasília/DF. Assessor Jurídico Regional do IEF MG. Professor de Direito Ambiental e Agrário nas Faculdades INESC e FACTU de Unaí (Unaí/MG/Brasil). E-mail: marcosguimaraes81@gmail.com

** Doutor Pesquisador do Programa de Pós-Graduação Stricto Sensu em Planejamento e Gestão Ambiental da Universidade Católica de Brasília (Brasília/DF/Brasil). E-mail: pauloricardorar@gmail.com
} 
environmental law as a standard of Superlaw, in the light of the principles governing this science, covering general aspects of environmental justice, Environmental Governance and Fundamental human right, in confrontation with Materials and legislative competences conferred to loved the Federation, respected the Principle of Federation.

\section{KEYWORDS:}

Environmental law; Federal Principle; Competence. Sobredireito; Municipality.

\section{INTRODUÇÃO}

A atuação dos municípios no que tange a preservação/conservação dos Recursos Naturais não obedecem as suas Competências mínimas elencadas na Constituição Federal de 1988, que via de regra define a Competência Legislativa dos Municípios como "SUPLEMENTAR" e a Competência Material ou Administrativa como "COMUM" entre os entes da federação, certo de que tal exercício encontra-se aquém dos termos descritos pelos pilares do Direito Constitucional e Ambiental, devendo-se avaliar os instrumentos necessários para viabilizar a efetiva atuação destes.

Em que pese às informações contidas acima, vale lembrar a orientação sobre Competência dos entes federativos fornecida pelo professor Alexandre de Moraes.

\footnotetext{
A autonomia das entidades federativas pressupõe repartição de Competências legislativas, administrativas e tributárias, sendo, pois, um dos pontos caracterizadores e asseguradores do convívio no Estado Federal.

A própria Constituição Federal estabelecerá as matérias próprias de cada um dos entes federativos, União, Estados-membros, Distrito Federal e municípios, e a partir disso, poderá acentuar a centralização de poder, ora na própria Federação, ora nos Estados-membros. (MORAES, 2003, p.287).
}

Desta feita, faz - se necessária a verificação dos conceitos de Federação, especialmente com a inteligência do Princípio Federativo que confere aos Estados - Membros e aos Municípios da Federação Brasileira status de entes autônomos, com relativa liberdade no que tange a sua administração, governo e organização, com fulcro nas normas limitadoras contidas na Constituição da República Federativa do Brasil.

Normas estas que passados 23 (vinte e três) anos da edição da festejada “Constituição Cidadã" permanecem cumprindo o seu objetivo histórico de manutenção do status quo ante, de garantir o poder centralizador e hegemônico, limitando de tal maneira a R. Fac. Dir. UFG, V. 40, n. 1, p. 209-226, jan. / jun. 2016 


\section{NATUREZA JURÍDICA DO DIREITO AMBIENTAL[...]}

possibilidades de atuação dos Estados-Membros, desrespeitando assim suas autonomias, e ainda relegando os municípios ao total estado vegetativo.

Nestes termos, cabe citar o conceito de federação fornecido pelo Mestre Dalmo de Abreu Dallari: “Os Estados federais são aqueles que, diferentemente dos Estados unitários, abrigam vários centros de poder político autônomo regulamentados pela Constituição Federal", sedimentando, portanto, o entendimento sobre a formatação dos chamados Estados federais. (DALLARI, 2005, p. 257).

Posto isto, é salutar o estudo do conceito de Competências e suas diversas espécies, tendo em conta o melhor entendimento sobre as Competências dos municípios, visando a debelação das dúvidas existentes sobre o tema.

Assim, urge a necessidade da apresentação do tema Direito Ambiental, salientando que esta é a ciência que se ocupa da preservação dos recursos naturais, especialmente procedendo com a regulação das relações humanas e seus meios de produção com a natureza, como forma de permitir o equilíbrio dessa relação, dando sustentabilidade ao desenvolvimento e minimizando os efeitos degradantes sobre o meio ambiente, com enfoque nas Competências Ambientais.

Por fim, será traçado um paralelo entre as Competências constitucionalmente deferidas a cada ente da federação e a natureza jurídica das normas ambientais, objetivando o alcance do entendimento de que os impactos sobre os recursos naturais são de natureza local, com repercussão global, portanto, entendendo a importância primordial dos municípios no exercício de suas Competências.

Assim, o presente texto contará com o estudo aprofundado do Conteúdo Constitucional referente às competências ambientais, bem como a utilização da legislação nacional esparsa, jurisprudências e posições internacionais quanto à natureza jurídica das normas de sobredireito.

\section{A BASE DO PRINCÍPIO FEDERATIVO}

O chamado Princípio Federativo fora adotado pela República Brasileira na definição de sua forma de Estado, conforme podemos aduzir do texto da Constituição da República Federativa do Brasil que em seu primeiro artigo determina: 
Marcos Batista Guimarães e Paulo Ricardo da Rocha Araújo

Art. $1^{\circ}$ A República Federativa do Brasil, formada pela união indissolúvel dos Estados e Municípios e do Distrito Federal, constitui-se em Estado Democrático de Direito e tem como fundamentos: [...] (grifo do autor).

Viu-se que o Estado brasileiro é formado por uma unidade central de poder com poderes maiores do que os das autonomias, e diversas subdivisões internas com parcelas de poder chamadas autonomias, sendo que uma das suas principais características é a indissolubilidade, sendo certo que este é o reflexo da presença marcante do Princípio Federativo na formatação do Estado Brasileiro.

Porém, urge a necessidade de aprimoramento desta relação do poder central com os demais entes federativos, para que efetivamente possamos exercer a parcela das autonomias destinadas, alcançando maior eficiência na gestão das questões ambientais.

A autonomia é a capacidade de cada entidade federativa, ou seja, a União, os Estados, o Distrito Federal e os Municípios, de gerir seus interesses dentro de um âmbito jurídico e territorial, previamente determinado pelo poder soberano, ou seja, o Poder Constituinte Originário.

Desta forma, verificamos que no estado federado os municípios são entes dotados de parcela do poder estatal, e que exercem funções de suma importância para a consecução dos princípios constitucionais, especialmente no que se refere à preservação dos recursos naturais, redundando, portanto na necessidade imediata de aplicação efetiva do texto Constitucional no que tange a real aplicação do Princípio Federativo em nosso País.

\section{O MUNICÍPIO COMO ENTE FEDERATIVO}

Em que pese à necessidade de regularização por norma complementar das Competências Comuns aos entes federativos, o que ainda não fora realizado, gerando diversos conflitos entre os entes da federação, bem como dificuldades interpretativas, para os fins deste estudo facilitará as conclusões que se buscam, pois, neste contexto de anomia, prevalece à competência comum entre os entes da federação.

Verifica-se que a competência Administrativa trata das funções básicas de gerência do Ente Federativo, ou seja, é a atuação concreta dos mesmos, assim, as atribuições de gerência estatal serão exercidas por todos os entes da federação, podendo, portanto, ser 


\section{NATUREZA JURÍDICA DO DIREITO AMBIENTAL[...]}

simultaneamente exercida, desde que respeitados os limites constitucionais, sendo este o entendimento de Competências Comuns.

A competência legislativa, que é a elaboração das leis, pode ser verificada nos artigos 22, 24 e 30, I, da Constituição Federal, e tem em seu texto sempre expresso o verbo "legislar".

Certo é que em matéria ambiental a repartição de Competências deverá ser realizada observando-se que cabe a União legislar sobre normas gerais, cabendo aos Estados Membros suplementar estas normas ou exercer a competência plena em sua ausência, sendo a competência plena exercida de forma precária com condição resolutiva, por fim aos municípios compete suplementar as normas federais e estaduais no que couber e legislar sobre assuntos de natureza local.

Objetiva-se com a repartição da competência entre os entes da federação assegurar a ampla e irrestrita participação da população na tomada de decisões, no que concerne à preservação dos recursos naturais por meio do acesso à informação.

Dito isto, averigua-se que a constituição federal de 1988 tem como um de seus Princípios norteadores a Publicidade de seus atos que redunda no direito à ampla informação sobre os aspectos ambientais.

Concluí-se ainda que os municípios são meros coadjuvantes no cumprimento das competências legislativas e materiais no que tange a preservação dos recursos naturais, sendo este um dos mais graves problemas enfrentados pela população brasileira, o que se pretende apresentar a solução para este celeuma jurídico no presente texto.

\section{A PRINCIPIOLOGIA DO DIREITO AMBIENTAL}

O estudo dos princípios que norteiam a aplicação das normas ambientais é de contumaz importância, pois, conforme será visto os mesmos possuem conotações extremamente especializadas, não sendo observados ou possuindo correlatos em nenhum outro ramo do Direito.

Os princípios do direito ambiental são em sua maioria de conteúdo Constitucional, originários de normas internacionais, principalmente das editadas na Convenção de Estocolmo (1992), Declaração do Rio (1992), bem como na Agenda 21, sendo certo que estes 
Marcos Batista Guimarães e Paulo Ricardo da Rocha Araújo

movimentos globais alçaram o Direito Ambiental as raias das Ciências Jurídicas Autônomas. (CUSTÓDIO, 2003, p. 03)

Vários são os princípios que norteiam o Direito Ambiental, portanto, a doutrina entende não ser um rol taxativo, mas sim exemplificativo. Assim, as classificações variam segundo o melhor entendimento realizado pelos doutrinadores.

Tais princípios foram enumerados de forma bastante eficiente por Jeferson Gonzaga, que em seu artigo intitulado Teoria Geral do Direito Ambiental realizou a aferição minuciosa dos princípios descritos por alguns dos maiores Doutrinadores Brasileiros, sendo eles MACHADO (1998), MILARÉ (2000), FIORILLO (2000) e SIRVINSKAS (2002).

Em resumo identificou o Princípio da Participação Comunitária, Princípio Democrático; Princípio da Prevenção (precaução ou cautela), Princípio do Desenvolvimento Sustentável; Princípio do Poluidor- Pagador (Responsabilidade Civil Objetiva; Prioridade da Reparação Específica do Dano Ambiental).

Nota-se ainda a presença do Direito Humano Fundamental, onde o homem detém o direito fundamental a sadia qualidade de vida, vivendo em um ambiente equilibrado onde lhes seja assegurada à dignidade da pessoa humana conforme preconizada pelo texto constitucional, sendo que tal defesa assegura ainda as presentes e futuras gerações. (GONZAGA, 2009, p.02)

Verificando-se o rol apresentado acima não restam dúvidas de que nos encontramos diante de uma Ciência Jurídica dotada daquilo que mais enobrece o DIREITO, que é a Luta pela Justiça, pela Dignidade das Pessoas, pela defesa do Direito Humano Fundamental e pelo respeito a ambiente em que vivemos.

Nesta esteira, cumpre verificar, a atuação municipal deve ser pautada de forma objetiva, observando os princípios acima enumerados, em especial o princípio do Direito Humano Fundamental, que justifica de forma inquestionável a natureza jurídica destas normas como sendo normas de sobredireito.

A validação de tais afirmações se afigura por meio do movimento de Justiça Ambiental, que trata não exclusivamente de normas jurídicas, mas sim da essência do que se busca com a edição das legislações, que nada mais é que a JUSTIÇA, como fim precípuo do DIREITO.

Justiça Ambiental refere-se ao tratamento justo e ao envolvimento pleno de todos os grupos sociais, independente de sua origem ou renda nas decisões sobre o acesso, ocupação e uso dos recursos naturais em seus territórios. Sendo premente a verificação de tais 


\section{NATUREZA JURÍDICA DO DIREITO AMBIENTAL[...]}

definições e aplicação no seio social, pois, as pessoas mais pobres estão mais vulneráveis e susceptíveis a atuação degenerativa nos ambientes em que vivem. (ACSSERALD, MELLO, BEZZERRA, 2009, p.35).

O termo Justiça Ambiental é um conceito aglutinador e mobilizador, por integrar a dimensão ambiental, social e ética da sustentabilidade e do desenvolvimento, freqüentemente dissociados nos discursos e nas práticas. Tal conceito contribui para reverter a fragmentação e o isolamento de vários movimentos sociais frente aos processos de globalização e reestruturação produtiva que provocam perda de soberania, desemprego, precariedade do trabalho e fragilizarão do movimento sindical e social como um todo.

Justiça ambiental, mais que uma expressão do campo do direito, assume-se como campo de reflexão, mobilização e bandeira de luta de diversos sujeitos e entidades, como sindicatos, associações de moradores, grupos de afetados por diversos riscos (como as barragens e várias substâncias químicas), ambientalistas e cientistas.

Posto isto, a justiça ambiental revela-se como um distinto paradigma na hermenêutica das normas jurídicas que, por vezes, antepõe-se - pelo seu esgotamento - ao Direito Ambiental - se o cidadão não tem direito a uma vida saudável, ou a gestão do ecosistêmico básico de seu território, qual a razão de ser do texto legal hierarquicamente superior? (MANIFESTO DE LANÇAMENTO DA REDE BRASILEIRA DE JUSTIÇA AMBIETAL, 2005).

\section{NATUREZA JURÍDICA DAS NORMAS AMBIENTAIS - "NORMAS DE SOBREDIREITO"}

As normas de Direito Ambiental podem ser entendidas como normas de Sobredireito, normas de organização ou normas de coordenação, pois, são normas instrumentais, que visam à regulação e funcionamento dos órgãos ou a informação quanto à aplicação das normas ou procedimentos técnicos, para assegurar a boa aplicação do arcabouço jurídico existente em nosso país.

Normas de Sobredireito são os regramentos que orientam a aplicação do direito substantivo, seja na sua natureza temporal (direito intergeracional) ou sua natureza prática (aplicação das normas). Trata-se efetivamente do que se pode chamar de "Direito sobre Direito", caracterizando-se por seu cunho eminentemente público, pois, tem como destinatário principal o Estado.

R. Fac. Dir. UFG, V. 40, n. 1, p. 209-226, jan. / jun. 2016

ISSN 0101-7187 
Sobre o assunto, pode-se destacar o entendimento de Arnaldo Vasconcelos : "Por normas de Sobredireito, podem ser entendidas as normas processuais, as de interpretação e fontes, normas de Direito intertemporal e as de Direito interespacial, ou Internacional Privado". Norma jurídica é, pois, aquela com a qual se faz ou se fabrica direito. Essa noção tornou-se muito grata aos culturalistas do direito que, a partir de Hegel, e com fundamento na sofistica grega, conceberam-no como obra simplesmente humana, a refletir o processo evolutivo e o grau de civilização de cada povo (VASCONCELOS, 1993, p. 163).

Assim, urge a necessidade de verificarmos parte dos ensinamentos do Grande Mestre Miguel Reale acerca do assunto:

O que caracteriza uma norma jurídica é o fato de ser uma estrutura proposicional enunciativa de uma forma de organização ou de conduta, que deve ser seguida de maneira objetiva e obrigatória.

As normas de coordenação ou de organização possuem um caráter instrumental, que visa à estrutura e funcionamento de órgãos, ou à disciplina de processo técnicos de identificação e aplicação de normas no intuito de garantir uma convivência jurídica ordenada. (REALE, 2002, p.95)

A percepção da presença e importância destas normas em nosso sistema jurídico é ressaltada pela Lei de Introdução ao Código Civil, Decreto-Lei n ${ }^{\circ}$. 4.657, de 04 de setembro de 1942, que segundo o magistral escólio da professora Maria Helena Diniz pode ser entendida assim:

\footnotetext{
A Lei de Introdução é uma lex legum, ou seja, um conjunto de normas sobre normas, constituindo o direito sobre direito ("ein Rechtsordenung", "Recht ueber Recht", "surdroit", "jus supra jura"), um superdireito, um direito coordenador de direito. Não rege as relações de vida, mas sim as normas de vida, uma vez que indica como interpretá-las ou aplicá-las, determinando-lhes a vigência eficácia, suas dimensões espácio-temporais, assinalando suas projeções nas situações conflitivas de ordenamentos jurídicos nacionais e alienígenas, evidenciando os respectivos elementos de conexão. (DINIZ, 2001, p. 04)
}

Corrobora este entendimento o Prof. Paulo de Bessa Antunes quando afirma que "o direito Ambiental não se encontra situado em "paralelo" a outros "ramos" do Direito, ou seja, o Direito Ambiental é um direito de coordenação entre estes diversos "ramos". E, nesta condição, é um Direito que impõe aos demais setores do universo jurídico o respeito às normas que o formam, pois o seu fundamento de validade é emanado diretamente da Norma Constitucional”. (BESSA, 2005, p. 21) 


\section{NATUREZA JURÍDICA DO DIREITO AMBIENTAL[...]}

A especialidade do Direito Ambiental pode ser percebida ainda pela verificação de seus Princípios orientadores, que são verdadeiros mandamentos preservacionistas que orientam as diversas legislações sobre a matéria ambiental, dentre eles podemos citar: Princípio do Direito Humano Fundamental, Responsabilidade, Democrático, Equilíbrio, Precaução, Limite, Prevenção e do Poluidor Pagador e etc.

Ainda sobre o tema vale ressaltar as brilhantes palavras do ilustre Professor Jesus Jordano Fraga, titular da Universidade de Sevilla:

El Derecho ambiental es un signo de nuestra era. El Derecho suele reflejar fielmente las preocupaciones de la humanidad y es por esta elemental razón que el Derecho ambiental existe y ha alcanzado su desarrollo actual. La preservación y promoción del medio ambiente, la implementación de un modelo de desarrollo sostenible es una preocupación de la Sociedad de nuestro tiempo y, por consiguiente, de su Derecho. Obviamente, la degradación ambiental es uno de los principales problemas a los que se enfrenta la humanidad. Un modelo de desarrollo erróneo planetario (con superpoblación, y, sobre todo, injusticia en la distribución de los recursos económicos, injusticia en las relaciones comerciales, política y políticos irresponsables a largo plazo) ha puesto en el punto de mira de todos los países la necesidad del respeto a las reglas de equilibrio natural para garantizar la integridad y renovación de los sistemas naturales. Se trata en definitiva, nada más y nada menos, que establecer las reglas de juego que hagan posible un medio ambiente equilibrado y sostenible para las generaciones actuales y futuras. (FRAGA, 2006, p. 10)

Por fim, sedimenta a Constituição da República Federativa do Brasil em seu Artigo 225, a importância da preservação dos recursos naturais, e de seus processos ecológicos, objetivando a manutenção da sadia qualidade de vida tanto para as presentes e futuras gerações, o que torna o Direito Ambiental uma ciência Transgeracional, conforme podemos aduzir do texto legal transcrito abaixo:

Art. 225. Todos têm direito ao meio ambiente ecologicamente equilibrado, bem de uso comum do povo e essencial à sadia qualidade de vida, impondo-se ao Poder Público e à coletividade o dever de defendê-lo e preservá- lo para as presentes e futuras gerações. (grifado pelo autor)

Nestes termos, pode-se concluir que o Direito Ambiental deve ser entendido como o conjunto de normas especialíssimas que visam à manutenção dos Recursos Naturais, bem como a manutenção da vida humana na terra.

O Direito possui uma função primordial que é o respeito aos seus princípios, para que se alcance o Bem Comum, assim, em que pese à quantidade absurda de normas que regem esta ciência, é preciso lembrar que a Lei em sentido estrito é um instrumento para a 
Marcos Batista Guimarães e Paulo Ricardo da Rocha Araújo

consecução da Justiça, e não deve ser utilizada para engessar o melhor entendimento nos assuntos ambientais.

\title{
5. OMISSÃO DOS MUNICÍPIOS EM MATÉRIAS AMBIENTAIS
}

A verificação da atuação dos municípios brasileiros no que diz respeito às matérias ambientais, tendo em vista as Competências Constitucionais conferidas a estes entes da federação, observando-se a natureza excepcional das normas de Direito Ambiental indicase um cenário preocupante no que tange a manutenção da qualidade de vida de seus habitantes.

A atuação do município deverá ser pautada pelas regras de competência acima enumeradas, tanto na questão Legislativa quanto Material, observadas ainda as disposições do Artigo 30 da Constituição que diz:

\author{
Art. 30. Compete aos Municípios: \\ I - legislar sobre assuntos de interesse local; \\ II - suplementar a legislação federal e a estadual no que couber.
}

Assim, no que diz respeito ao inciso II do mencionado artigo, "suplementar" significa acrescentar, completar, o que parece simples, mas na realidade não se aplica uma vez que existem milhares de normas e todas muito conflitantes, o que acaba por impedir uma atuação plena dos entes municipais.

A questão essencial é o entendimento do que seria "Interesse Local", e quanto a isto definiu Paulo Affonso com maestria:

O "interesse local" não precisa incidir ou compreender, necessariamente, todo o território do Município, mas uma localidade, ou várias localidades, de que se compõe um Município. Foi feliz a expressão usada pela Constituição Federal de 1988. Portanto, pode ser objeto de legislação municipal aquilo que seja da conveniência de um quarteirão, de um bairro, de um subdistrito ou de um distrito.

A noção de interesse local não é unívoca. Haverá interesses locais em choque e, muitas vezes, encontraremos o interesse local pelo desenvolvimento econômico não sustentado ou imediatista, em antagonismo com o interesse local, pela conservação do meio ambiente.

Celso Bastos, José Cretela Júnior, Hely Lopes Meirelles, dentre outros de nossos publicistas eminentes, manifestam-se no sentido de que o interesse local não se 


\title{
NATUREZA JURÍDICA DO DIREITO AMBIENTAL[...]
}

caracteriza pela exclusividade do interesse, mas pela sua predominância. (MACHADO, 2004, p. 364)

Assim, verifica-se que o conceito de interesse local é mais abrangente do que se possa imaginar, uma vez que pode se referir a uma parcela territorial pequena da unidade federativa ou ate mesmo a outros interesses de natureza programáticos oriundos da administração municipal.

Vale destacar o magistério do professor Hely Lopes Meireles, no que tange ao interesse local:

\begin{abstract}
Muitas, entretanto, são as atividades que, embora tuteladas ou combatidas pela União e pelos Estados membros deixam remanescer aspectos da competência local, e sobre os quais o Município não só pode como deve intervir, atento a que a ação do Poder Público é sempre um poder-dever. Se o Município tem o poder de agir em determinado setor, para amparar, regulamentar ou impedir uma atividade útil ou nociva à coletividade, tem, corretamente, o dever de agir, como pessoa administrativa que é armada de autoridade pública e de poderes próprios para a realização de seus fins. (MEIRELLES, 1991, P.310)
\end{abstract}

Percebe-se pelas palavras do grande jurista citadas acima, que cabe aos municípios uma atuação efetiva no que tange a preservação dos recursos naturais, não só como um conjunto de atribuições definidas pela constituição, mas sim como um dever de cuidado com o meio ambiente, e conseqüentemente com os munícipes.

Em que pese à dificuldade de se conceituar o termo "Interesse Local", devemos interpretar as normas de Direito Ambiental, como dito em capítulo anterior, como regras de Sobredireito, de coordenação, pois, é de conhecimento geral, a complexidade do estudo do tema Competência neste ramo do direito.

Afigura-se como assunto complexo, pois, a diversidade de atribuições conferidas aos entes da federação são várias, e estes por diversas vezes não se entendem quanto aos limites de suas Competências, especialmente no que se refere às questões legislativas.

Como visto, cabe a União estabelecer Normas Gerais, aos Estados normas de caráter Regional e aos municípios o Interesse Local, porém, em diversas situações esta ordem constitucional é invertida, ocorrendo uma invasão na esfera de Competências dos entes federativos, o que acarreta a inconstitucionalidade da norma invasora.

Assim, é forçosa a seguinte reflexão: A provável declaração de inconstitucionalidade de uma norma que invade a esfera de competência de um ente da 
federação é o efeito que os princípios do Direito ambiental esperam, verificada a sua característica de Sobredireito?

A resposta é clara, diante do estudo do princípio mais relevante desta ciência, o Princípio da Prevenção, que segundo Milaré significa: "precaução é substantivo do verbo precaver-se (do latim prae $=$ antes e cavere $=$ tomar cuidado), e sugere cuidados antecipados, cautela para que uma atitude ou ação não venha resultar em efeitos indesejáveis". (MILARÉ, 2004, p. 114)

O Princípio em comento refere-se à atuação mais cautelosa no que se refere à preservação ambiental, pois, em se tratando de degradação dos recursos naturais nós observaremos danos de características muitas vezes irreversíveis, e de consequiências que podem ser catastróficas, tanto para a humanidade quanto para todo o ecossistema.

Prevenir significa antever os possíveis impactos ambientais, ter certeza dos danos que serão causados e poder aferir o custo benefício de cada impacto, neste sentido ensinou Fiorillo: “[...] a efetiva prevenção do dano deve-se também ao papel exercido pelo Estado na punição correta do poluidor, pois, dessa forma, ela passa a ser um estimulante negativo contra a prática de agressões ao meio ambiente". (FIORILLO, 2001, p. 36)

O referido princípio pode ser entendido como as medidas efetivas a serem tomadas antes da existência do nexo causal entre a ação humana e a degradação ambiental, conceito este fornecido pela Conferência de Londres de 1987.

\footnotetext{
Accepting that, in order to protect the North Sea from possibly damaging effects of the most dangerous substances, a precautionary approach is necessary which may require action to control inputs of such substances even before a causal link has been established by absolutely clear scientific evidence. (UNESCO, 2005, p.12)
}

Desta forma, pode-se aduzir que a prevenção cabe a todos os entes da federação, como detentores do Poder de Polícia que são, e neste sentido o ente que mais se apresenta como capaz de fazer cumprir os objetivos de preservação é o município.

Assim, o município reúne os cidadãos, que são os integrantes da cidade em seu conceito clássico advindo da Grécia, portanto, hodiernamente cidadão é o indivíduo que participa ativamente das decisões políticas e administrativas da localidade em que vive, cumprindo com todas as obrigações que decorrem da vida em sociedade.

Os integrantes do seio social são compelidos a cumprir normas ambientais por meio de regras punitivas e obrigações impostas, que para a grande maioria das pessoas não fazem o menor sentido, desta forma, sentem-se fora do processo de preservação, sendo certo 


\title{
NATUREZA JURÍDICA DO DIREITO AMBIENTAL[...]
}

que a simples adoção de penalidades não alcança os objetivos do Direito Ambiental, como podemos perceber pelas palavras do Professor Álvaro Sanches Bravo:

\begin{abstract}
Sin recaer de nuevo en la constatacion del fracaso de las formulas protectoras ensayadas, si conviene sealar que la sola apelacion al Derecho penal no bastar per se para erradicar los atentados al medio ambiente. Em primer lugar, por que el derecho penal tender fundamentalmente a reprimir, a castigar una vez el dalo se haya inferido. Al margen de los clasicos fines asignados al derecho penal (prevencion general y especial), la funcion preventiva requiere de otros mecanismos y de otras implicaciones. (SANCHES, 2006, p.38)
\end{abstract}

O município é a menor esfera de poder existente em nosso Estado, tanto na esfera territorial, quanto administrativa, o município pode-se dizer que é o único ente "Real", ou seja, é formado por território e pessoas, não que os demais entes não o sejam, mas os Estados são a junção de vários municípios, e a União é uma ficção ainda maior, que é a junção de Estados - Membros, todos estes amparados pela estrutura municipal.

Logo, o município agrega as condições ideais para Planejar e Gerir os aspectos ambientais locais através de um monitoramento mais efetivo, a fim de adquirir a mais completa gama de informações, fornecendo assim uma resposta política efetiva, assegurando o Desenvolvimento Sustentável de sua região. (DERANI, 2005, p.650)

Dito isto, entende-se que a competência local é a mais relevante dentre todas, pelo fato de tratarem diretamente com as pessoas, que resumidas a povo perdem muito da sua individualidade, devendo ser vistas novamente como Seres Humanos, assegurados os seus direitos fundamentais.

Sobre a reflexão outrora realizada ficou clara a intenção de se comprovar que as normas de Direito Ambiental, como regras de sobredireito que são merecem uma atenção redobrada, e o respeito ao Princípio da Prevenção e Direito Humano Fundamental, prescindindo-se de análises frias das normas e privilegiando a proteção dos recursos naturais, mesmo que para isso ocorra a supressão de Competências por parte de algum ente da federação.

Urge a necessidade, portanto, de uma busca pelo Desenvolvimento Sustentável verificando-se um equilíbrio ético entre o presente e o futuro, verificando-se um conteúdo moral das normas ambientais, se garantido a equidade no Direito de Desenvolver, cabendo tal função essencialmente aos municípios. 
Ainda sobre o conteúdo ético das normas ambientais, expõe-se o posicionamento exarado pelo World Commission on the Ethics of Scientific Knowledge and Technology da UNESCO:

The classic conception of sustainable development implies that the needs of present generations should be met provided they do not impair the ability of future generations to meet their needs. This implies an ethical balance between present and future generations. There is ample reason to say that as a moral norm intergenerational equity is not entirely new, but implied by traditional moral claims of universality and justice. The fact that it has been formulated in an explicit manner quite recently may be seen as the result of the recognition that many of our (technological and other) actions and decisions today have far-reaching consequences into the future (as, for example, storage of radioactive material). (UNESCO, 2005, p.19)

Deste modo, mesmo que o município no exercício de suas atividades preservacionistas invada a esfera de Competências da União ou dos Estados tanto na questão legislativa, quando na esfera administrativa, o mesmo estará cumprindo o seu papel enquanto representante máximo dos interesses de seu povo.

Porém, vale ressaltar que a presente reflexão aplica-se a complementação, suplementação ou elaboração de novas normas que sejam mais benéficas para o meio ambiente, para que no futuro administradores não se valham destes argumentos para editar normas prejudiciais ao ambiente, em favor de interesses escusos.

Enfim, a decretação da inconstitucionalidade de uma norma mais benéfica ao meio ambiente, ou uma nova legislação que regule situação não antes verificada, não alcança os objetivos do Direito Ambiental, especialmente no que tange ao cumprimento do Princípio da Prevenção.

Certo é que deve prevalecer o otimismo nestas questões, acreditar que as autoridades municipais atuarão com probidade, visando o bem comum, somente em caso contrário que a força do Poder Judiciário deverá ser utilizada para anular ou invalidar atos que por ventura destoem do interesse público.

Desta forma, em que pese às severas críticas feitas contra o Licenciamento Ambiental, este ainda é o mecanismo mais eficaz de preservação ambiental que se tem comprovação dos efeitos, juntamente com a Educação Ambiental, que não será discutida neste momento por claramente ser competência comum dos 03 (três) entes da federação.

O Licenciamento merece destaque por ser exercido de forma muito tímida pelos municípios, estando presente esta estrutura avaliadora em pouquíssimas cidades do Brasil. 


\section{NATUREZA JURÍDICA DO DIREITO AMBIENTAL[...]}

Como visto acima, a competência material para a preservação ambiental cabe a todos os entes da federação, porém, o exercício da atividade de licenciamento possui uma grande ressalva legislativa, e procedimental, uma vez que os municípios abdicam do exercício desta atividade, bem como a União e Estados se arvoram deste direito de forma exclusiva.

Em suma, vê-se o absurdo das normas pátrias, que engessam a atuação dos entes municipais, mesmo que estes possuam a estrutura licenciadora estarão subordinados à autoridade de outros entes, tolhendo assim, a sua competência para decisão dos assuntos locais.

Assim, os municípios devem atuar com firmeza e instituir sua estrutura para o licenciamento, para que possam efetivamente contribuir para a preservação dos Recursos Naturais, que como sabido sofrem impactos inicialmente locais, que podem gerar conseqüências Regionais ou Nacionais.

Enfim, as normas ambientais pátrias serão efetivamente aplicadas e alcançarão seus fins, quando a sociedade brasileira passar a entender que as mesmas são objetos necessários para o alcance da JUSTIÇA, especialmente da Justiça social e ambiental, sendo necessária a imediata mudança na interpretação jurídica destas normas, conferindo aos municípios as responsabilidades inerentes a sua existência e que a muito lhe são negadas.

\section{CONCLUSÃO}

Em sede de conclusões, deve-se salientar que não se pretende esgotar a temática das Competências municipais no que tange a aplicação das normas ambientais, bem como na efetiva preservação dos recursos naturais.

Certo é que não haverá momento mais oportuno para que se possa discutir as complexas relações existentes entre os entes da federação, onde as relações de poder não se alteram, o que há é um arremedo de gestão ambiental democrática, contrariando frontalmente os princípios constitucionais e especialmente do Direito Ambiental.

Os governos são autoritários e centralizadores, valem-se da fragilidade do Poder Judiciário Brasileiro para editarem normas inconstitucionais e injustas, a União que tem competência para legislar em caráter geral em vários momentos extrapola estes limites, sendo certo que os Estados-membros acompanham tal pensamento. 
Marcos Batista Guimarães e Paulo Ricardo da Rocha Araújo

Assim, os municípios são alijados de suas competências, participando dos processos decisórios apenas como coadjuvantes, não são respeitados em suas autonomias, tão pouco no que é o obvio da gestão ambiental, que é a atuação efetiva da comunidade.

Posto isso, sabendo-se que o município é o ente real desta ficção chamada de Estado, bem como a relação dos impactos ambientais com a máxima "danos locais e impactos globais", conclui-se que o município é o ente legítimo e mais capacitado para atuar nas lides referentes à preservação ambiental.

Porém, tais afirmações não são fundadas em aspectos empíricos, buscou-se comprovar acima que existe sim fundamentação legal para tal transferência de responsabilidades.

Através da avaliação profunda dos aspectos inerentes ao caso ficou demonstrado que o Princípio Federativo autoriza a distribuição de competências entre os entes do Estado, que a Constituição pátria defere competências aos municípios, e que mesmo o texto da carta magna não sendo explícitos, os princípios gerais do direito ambiental indicam que está ciência possui natureza jurídica de Normas de Sobredireito, portanto, em determinados momentos serão superiores hierarquicamente ao texto constitucional.

Fica, portanto a reflexão: do que adianta a constituição e o conjunto de normas jurídicas se não mais houver os bens jurídicos a serem preservados, em especial a vida humana ou sua dignidade?

Entretanto, urge a necessidade de uma drástica mudança na hermenêutica jurídica para que o status quo do estudo do direito seja transformado em algo menos burocrático e mais efetivo, voltado ao cumprimento dos princípios gerais do direito ambiental em especial o alcance da tão almejada Justiça Ambiental em respeito ao Direito Humano Fundamental.

\section{REFERÊNCIAS}

ACSELRAD, H. MELlO A. C. C. BEZERRA. N. G. O que é justiça ambiental. 02. ed. Rio de Janeiro: Garamound. 2009.

BESSA, A. P. Direito ambiental. 8. ed. Rio de Janeiro: Lúmen Júris. 2005.

BRASIL. Constituição (1988). Constituição da República Federativa do Brasil. Brasília, DF: Senado Federal. 2004.

CUSTÓDIO, B. H. Governos Locais e meio ambiente: repercussões nacionais e internacionais. 2003. Disponível em: R. Fac. Dir. UFG, V. 40, n. 1, p. 209-226, jan. / jun. $2016 \quad$ ISSN 0101-7187 


\section{NATUREZA JURÍDICA DO DIREITO AMBIENTAL[...]}

http://www.egov.ufsc.br/portal/sites/default/files/anexos/14428-14429-1-PB.pdf >. Acesso em: 31 mar. 2012.

DALLARI, D. A. Elementos de teoria geral do estado. 25. ed. São Paulo: Saraiva. 2005.

DERANI, C. Aplicação dos princípios do direito ambiental para o desenvolvimento sustentável. In: TORRES, H. T. (Org.). Direito tributário ambiental. São Paulo: Malheiros. 2005.

DINIZ, M. H. Lei de introdução ao código civil brasileiro interpretada. 7 ed. São Paulo: Saraiva. 2001.

FIORILLO, C. A. P. Curso de direito ambiental brasileiro. 2.ed. São Paulo: Saraiva. 2001. FRAGA, J. J. El derecho ambiental del Siglo XXI. Revista Derecho Ambiental, Lima, v. 01, n. 1, p. 01. dez. 2006. Disponível em: < http://huespedes.cica.es/aliens/gimadus/jjordano.html >. Acesso em: 31 mar. 2012.

GONZAGA, J. Teoria geral do direito ambiental brasileiro: noções de direito ambiental brasileiro. 2009. Disponível em: < http://www.webartigos.com/artigos/principios-do-direitoambiental/13342/ >. Acesso em: 20 set. 2011.

MACHADO, P. A. L. Direito ambiental brasileiro. 12. ed. São Paulo: Malheiros. 2004.

MEIRELLES, H. L. Direito administrativo brasileiro. 19. ed. São Paulo: Malheiros. 1991.

MILARÉ, E. Direito do ambiente: doutrina, jurisprudência, prática, glossário. 3. ed. São Paulo: Revista dos Tribunais. 2004.

MORAES, A. Direito constitucional. 13. ed. São Paulo: Atlas. 2003.

REALE, M. Lições preliminares de direito. 27 ed. São Paulo. Saraiva. 2002.

REDE BRASILEIRA DE JUSTIÇA AMBIENTAL. Manifesto de lançamento da Rede Brasileira de justiça ambiental. 2005. Disponível em:

<http://www.justicaambiental.org.br/_justicaambiental/pagina.php?id=229>. Acesso em: 31 mar. 2012.

SANCHES BRAVO, A. A. Protección penal del medio ambiente en la Unión Europea. Hiléia: Revista Eletrônica de Direito Ambiental da Amazônia, Manaus, v. 04, n. 7, p. 38 dez. $2006 . \quad$ Disponível em: < http://www.pos.uea.edu.br/data/direitoambiental/hileia/2005/4.pdf >. Acesso em: 31 mar. 2012.

UNESCO. COMEST. The precautionary principle. Paris: UNESCO. 2005. Disponível em: < http://unesdoc.unesco.org/images/0013/001395/139578e.pdf>. Acesso em: 31 mar. 2012.

VASCONCELOS, A. Teoria geral do direito: teoria da norma jurídica. 3. ed. São Paulo: Malheiros. 1993. 
Marcos Batista Guimarães e Paulo Ricardo da Rocha Araújo

Artigo recebido em 25 de abril de 2012 e aceito em 18 de dezembro de 2015 